energy function as quadratic. But the purpose of investigating the response to destructive earthquake motions requires consideration of strains much exceeding the limits within which Hooke's Law remains valid., According to the author, the linear theory can then only be used as a first approximation and the effects of the various components of ground motion cannot be treated separately. The Rayleigh dissipation function may be important but the case of small damping including the existence of normal modes of oscillation has been encountered in the case of buildings, bridges and tank towers. The paper will act as a signpost towards further progress in mathematical seismology.

\section{Epicentres of the Earthquakes of April 20 and 2I}

The U.S. Coast and Geodetic Survey, in co-operation with Science Service and the Jesuit Seismological Association, has determined the provisional epicentres of two recent strong earthquakes. The first on April 20 , 1941, at $17 \mathrm{~h} .38 \cdot 3 \mathrm{~m}$. G.M.T., had an epicentre near lat. $37^{\circ} \mathrm{N}$., long. $69^{\circ} \mathrm{E}$., which is in Afghanistan and some 160 miles north of Kabul. The second, on April 21, 1941, at $2 \mathrm{~h} .54 \cdot 1 \mathrm{~m}$. G.M.T. was near lat. $53^{\circ} \mathrm{N}$., long. $166^{\circ} \mathrm{W}$. which is in the neighbourhood of the Aleutian Islands. Both these areas are well known to be frequented by earthquakes, the Aleutian Islands area having been particularly active in recent months.

\section{Forestry in Uganda}

IN the annual report for the year ending December 31, 1940 (Entebbe, Govt. Printer, Uganda, 1941), the Conservator, after detailing the total areas of forest under control, says that under a reclassification of the forests the area of protection reserves has increased at the expense of production reserves. Fxcept for forty-eight square miles of high forest, all the new areas gazetted were savannah land or bush-covered hills with some gallery forest in the valleys. For those with an acquaintance of local African conditions this reservation of savannah and bush lands is of the greatest significance and the Forest Department may be congratulated on its action. It is not the less disturbing, therefore, to read that "Reconnaissance continued on a reduced scale and there are still some 1,000 square miles in the Eastern and Western Provinces which are known to require reservation. In Buganda the need for reconnaissance and reservations was recognized by Government, but staff was not available to make a start." This question, the inadequacy of staff, has interrupted other valuable work in progress. It cannot but be disheartening to Forest Departments when the Administration responsible are unable to realize that forest property and management differ widely from the short-term (in years) policy with which agricultural lands can be treated. In the general interests of the communities as a whole, especially when more or less directly dependent upon the forests, not even the stresses of an Empire War should be allowed to imperil the future of such forest areas.

\section{The Health of Canada}

THE April issue of the Statistical Bulletin issued by the Metropolitan Life Insurance Company of New York contains an instructive editorial on the health of Canada in 1940. During the last three months of 1939 and almost the whole of 1940 the mortality record in Canada was very favourable; but it showed some rise in December and the first quarter of 1941 owing to the epidemic of influenza which occurred at the end of 1940. As a whole, however, the standardized death-rate of the Canadian Industrial policy holders less than seventy-five years of age was only $592 \cdot 1$ per 100,000 , or $12 \cdot 1$ per cent below the average rate for the five preceding years. Among children the drop in mortality was as much as 30 per cent. The greatest improvement took place in the acute and infectious conditions, while cancer and diabetes showed higher rates than in previous years. The decline in the principal infectious diseases in children, namely, measles, scarlet fever, whooping cough and diphtheria was 43 per cent since 1935-39. For measles and scarlet fever the rate was less than two thirds of the average for the preceding five years, and for diphtheria the 1940 rate was little more than one half of the earlier rate. Whooping cough, with a rate of 5.1 per 100,000 in 1940 , or more than that for the other three combined, is to-day the most serious of these diseases of childhood. Diseases of the heart, arteries and kidneys together accounted for more than one third of the mortality. As regards tuberculosis the death-rate for the first time fell below 50 per 100,000 , the decline since 1935 being 15 per cent. Child-bearing has become definitely safer in Canada, the puerperal death-rate having fallen to 6.2 per 100,000 in 1940 from 9.0 in the preceding five-year period. Lastly, there was an appreciable decline in deaths from violence.

\section{Public Health in Haiti}

According to Dr. Rulx Léon, Under-Secretary of State in Charge of the Health Service and Public Assistance, a major concern of the Health Service of Haiti is the lack of adequate drinking-water facilities, which is particularly serious in the capital. During the past year, the Government created a public welfare organization which established several hospitals in different parts of the country. 31,202 cases of malaria were treated in hospitals and Government rural clinies. Dysentery and intestinal parasitism existed in endemic form. Outbreaks of measles, ringworm and influenza were quickly controlled. A mild epidemic of diphtheria broke out in the capital. The principal causes of death were tuberculosis, malaria, enteritis, syphilis and pneumonia. A total of 47,950 births and 12,907 deaths was recorded.

\section{Historical Medicine and Science}

UNDER the title of "Medical Miscellany : List A" Schuman's, of 730 Fifth Avenue, New York, have published a catalogue of 150 works of historical medicine and science. Of special interest are Abernethy's Hunterian Oration for 1819, von Behring's early contributions on the specific treatment 